\title{
CITED2 modulation of trophoblast cell differentiation: insights from global transcriptome analysis
}

\author{
Kazuhiko Imakawa', ${ }^{1,}$ Pramod Dhakal'², Kaiyu Kubota², Kazuya Kusama , \\ Damayanti Chakraborty², M A Karim Rumi² and Michael J Soares ${ }^{2}$ \\ ${ }^{1}$ Laboratory of Theriogenology and Animal Breeding, The University of Tokyo, Bunkyo-ku, Tokyo, Japan and \\ ${ }^{2}$ Department of Pathology and Laboratory Medicine, Institute for Reproductive Health and Regenerative Medicine, \\ University of Kansas Medical Center, Kansas City, Kansas, USA \\ Correspondence should be addressed to K Imakawa; Email: akaz@mail.ecc.u-tokyo.ac.jp or M J Soares; Email: msoares@kumc.edu
}

\begin{abstract}
Trophoblast stem (TS) cells possess the capacity to differentiate along a multi-lineage pathway yielding several specialized cell types. The regulatory network controlling trophoblast cell differentiation is poorly understood. $\mathrm{Cbp} / \mathrm{p} 300$-interacting transactivator with Glu/Asp-rich carboxy-terminal domain, 2 (CITED2) has been implicated in the regulation of placentation; however, we know little about how CITED2 acts to influence trophoblast cells. Rat Rcho-1 TS cells can be manipulated to proliferate or differentiate into specialized trophoblast lineages and are an excellent model for investigating trophoblast differentiation. CITED2 transcript and protein showed a robust induction during Rcho-1 TS cell differentiation. We used an shRNA knockdown approach to disrupt CITED2 expression in order to investigate its involvement in trophoblast cell differentiation. RNA-sequencing was used to examine the impact of CITED2 on trophoblast cell differentiation. CITED2 disruption affected the differentiating trophoblast cell transcriptome. CITED2 possessed a prominent role in the regulation of cell differentiation with links to several signal transduction pathways and to hypoxia-regulated and coagulation processes. In summary, our findings indicate that CITED2 contributes to the regulation of trophoblast cell differentiation. Reproduction (2016) 151 509-516
\end{abstract}

\section{Introduction}

The placenta has a diverse set of responsibilities ensuring the survival, growth, and development of the embryo/fetus within the mother's reproductive tract (Amoroso 1968, Cross et al. 1994, Geogiades et al. 2002). In most primates and rodents, these tasks are accomplished through the formation of a hemochorial placenta where maternal blood directly bathes specialized extraembryonic cells termed trophoblast. The hemochorial placenta, through the activities of trophoblast cells, modifies maternal physiology via intrauterine migration and vascular remodeling and the production of hormones/cytokines (Cross et al. 1994, Pijnenborg et al. 2006, Soares et al. 2014). The hemochorial placenta also regulates the bidirectional transport of nutrients and wastes between the mother and the fetus (Sibley et al. 1997, Knipp et al. 1999, Watson \& Cross 2005, Dilworth \& Sibley 2013). Execution of these functions requires coordinated temporal and spatial differentiation of stem and progenitor cells into specialized trophoblast cell types and their organization into a hemochorial placenta (Roberts \& Fisher 2011). The rat has proven to be a superb model for investigating hemochorial placentation (Soares et al. 2012).
A mature rat hemochorial placenta consists of two major compartments, the junctional zone and the labyrinth zone (Soares et al. 1996, 2012). The junctional zone lies at the maternal-placental interface and is composed of progenitor cells, which differentiate into four distinct specialized trophoblast cell types. Trophoblast giant cells are large polyploid cells arising by endoreduplication. They possess a remarkable capacity for steroid and peptide hormone biogenesis (Soares et al. 1996, Soares 2004). Spongiotrophoblast cells are a major constituent of the mature junctional zone and produce peptide hormones. Glycogen trophoblast cells accumulate glycogen and are viewed as an energy reservoir for the developing placenta and fetus. Junctional zone progenitors also give rise to invasive trophoblast cells, which exit the placenta and infiltrate the uterine compartment where they target and facilitate uterine spiral artery remodeling and the delivery of nutrients to the placenta (Ain et al. 2003, Soares et al. 2014). In contrast, the labyrinth zone is situated at the placental-fetal interface and consists of progenitor cells, which can differentiate into trophoblast giant cells or fuse to form syncytial trophoblast (Soares et al. 2012). The latter cell layers form the barrier between maternal and fetal compartments and 
directly connect with fetal vasculature and promote bidirectional transport (Knipp et al. 1999). Trophoblast cell differentiation can be effectively modeled in Rcho- 1 trophoblast stem (TS) cells (Faria et al. 1991, Sahgal et al. 2006). Rcho-1 TS cells were derived from a rat choriocarcinoma (Teshima et al. 1983) and can be maintained in the stem/progenitor state or the culture conditions can be modified resulting in their differentiation into specialized trophoblast lineages, including but not limited to trophoblast giant cells (Faria et al. 1991, Sahgal et al. 2006). Transcriptome profiles of Rcho- 1 TS cells in the stem and differentiated states reflect the known behavior of trophoblast cell lineages developing in the rat hemochorial placenta (Kent et al. 2010).

Several signaling pathways have been implicated in the regulation of trophoblast development (Soares et al. 2014). Among these pathways, hypoxia-inducible factor (HIF) and Fos-like antigen 1/Jun B protooncogene transcriptional regulators have been shown to influence the regulation of trophoblast cell differentiation in mice, rats, and humans (Schorpp-Kistner et al. 1999, Adelman et al. 2000, Caniggia et al. 2000, Schreiber et al. 2000, Chakraborty et al. 2011, Kent et al. 2011, Renaud et al. 2014, Kubota et al. 2015). Both transcription factor complexes recruit histone acetyl transferases, CREB-binding protein (CREBBP), and E1A-binding protein p300 (EP300) in activating their gene targets (Vo \& Goodman 2001, Bedford et al. 2010, Semenza 2010).

Cbp/p300-interacting transactivator with Glu/ Asp-rich carboxy-terminal domain, 2 (CITED2) is a transcriptional co-regulator that regulates interactions between DNA-binding proteins and histone-modifying enzymes, including transcription factor-CREBBP/ EP300 interactions (Braganca et al. 2003, Freedman et al. 2003). CITED2 is widely expressed in embryonic and extraembryonic tissues, is required for normal development of the embryo and placenta (Bamforth et al. 2001, Barbera et al. 2002, Yin et al. 2002, Weninger et al. 2005, Withington et al. 2006, Moreau et al. 2014), and is also expressed in the uterus where it is essential for embryo implantation (Yoo et al. 2015). CITED2 has been implicated in the regulation of two transcription factor families: transcription factor-activator protein 2 (TFAP2) and HIF (Bhattacharya et al. 1999, Bamforth et al. 2001, Yin et al. 2002, Braganca et al. 2003, Freedman et al. 2003). Members of these transcription factor families are significant contributors to the regulation of trophoblast cell differentiation (Simon \& Keith 2008, Dunwoodie 2009, Chakraborty et al. 2011, 2012, Kuckenberg et al. 2012); however, specific roles for CITED2 in regulating trophoblast cell differentiation have not been determined.

CITED2 is dynamically regulated during rat trophoblast cell development (Kent et al. 2010), and based on mouse mutagenesis, experimentation contributes to development of both junctional and labyrinthine tro- phoblast lineages (Withington et al. 2006, Moreau et al. 2014). In this study, we explore the roles for CITED2 in the regulation of trophoblast cell differentiation. We utilize an in vitro loss-of-function approach and RNAsequencing (RNA-seq) to identify targets downstream of CITED2 action.

\section{Materials and methods}

\section{Rcho-1 TS cell culture}

Rcho-1 TS cells are an effective model system for interrogating regulatory pathways controlling rat trophoblast cell differentiation (Faria \& Soares 1991, Kent et al. 2010, 2011, Kubota et al. 2015) and are used to investigate a role for CITED2 in the regulation of trophoblast cell differentiation. Rcho- 1 TS cells were maintained in Stem State Medium (RPMI-1640 culture medium (Gibco-Life Technologies) supplemented with 20\% fetal bovine serum (Atlanta Biologicals, Norcross, GA, USA), $50 \mu \mathrm{M}$ 2-mercaptoethanol (Sigma-Aldrich), $1 \mathrm{mM}$ sodium pyruvate, $100 \mu \mathrm{M}$ penicillin, and $100 \mathrm{U} / \mathrm{mL}$ streptomycin), as previously reported (Faria \& Soares 1991, Sahgal et al. 2006). Rcho-1 TS cells were grown to near confluence and differentiation was induced by replacing the Stem State Medium with Differentiation State Medium (NCTC-135 medium (Sigma-Aldrich) supplemented with $1 \%$ horse serum (Atlanta Biologicals), $50 \mu \mathrm{M}$ 2-mercaptoethanol, $1 \mathrm{mM}$ sodium pyruvate, $10 \mathrm{mM}$ HEPES, 4-(2-hydroxyethyl)-1-piperazineethanesulfonic acid, $38 \mathrm{mM}$ sodium bicarbonate, $100 \mu \mathrm{M}$ penicillin, and $100 \mathrm{U} / \mathrm{mL}$ streptomycin).

\section{CITED2 knockdown}

An shRNA knockdown approach was used to disrupt CITED2 expression in Rcho-1 TS cells and to investigate the role of CITED2 in trophoblast cell differentiation. Three different Cited shRNAs (shCited2-1: 5'-gaagctcaacaaccagtatttc-3'; shCited2-2: 5'-catcgacgaggaagtgcttatctc-3'; and shCited2-3: 5'-agaagctcaacaaccagtatt-3'; Sigma-Aldrich) and a control shRNA (shCtrl, plasmid no. 1864; Addgene, Cambridge, MA, USA) were packaged into lentiviral vectors and used to produce lentiviral particles in 293FT cells (Kent et al. 2011, Asanoma et al. 2012). Culture supernatants containing lentiviral particles were harvested, centrifuged to remove cell debris, filter sterilized, concentrated by ultracentrifugation, and stored at $-80^{\circ} \mathrm{C}$ until used. Rcho- 1 TS cells maintained in Stem State Medium were exposed to lentiviral particles, selected with puromycin dihydrochloride $(2 \mu \mathrm{g} / \mathrm{mL}$; Sigma-Aldrich) for 2 days, and then maintained in a lower concentration of the antibiotic $(1 \mu \mathrm{g} / \mathrm{mL})$. Puromycin selection was removed during in vitro differentiation. Knockdown efficiencies were monitored using quantitative RT-PCR (qRT-PCR) and western blotting.

\section{qRT-PCR}

Transcript levels were measured by qRT-PCR. RNA was extracted using TRI reagent (Sigma-Aldrich) according to the manufacturer's instructions. cDNAs were reverse transcribed 
using a High-Capacity cDNA Reverse Transcription Kit from Applied Biosystems as instructed by the manufacturer. Power SYBR Green PCR Master Mix (Applied Biosystems) was used in the PCR. Primers utilized in the analyses are provided in Table 1. Amplification and fluorescence detection were carried out using an ABI Prism 7500 Real-Time PCR System (Applied Biosystems). The thermal profile for real-time PCR consisted of an initial hold step $\left(95^{\circ} \mathrm{C}\right.$ for $\left.10 \mathrm{~min}\right)$ and 40 cycles at $95^{\circ} \mathrm{C}$ for $15 \mathrm{~s}$ and annealing at $60^{\circ} \mathrm{C}$ for $1 \mathrm{~min}$. Amplification efficiencies of each target and the reference gene, 185 rRNA, were examined through their calibration curves and found to be comparable. Average cycle threshold values for each target were determined by Sequence Detection System Software v1.2 (Applied Biosystems). Each run was completed with a melting curve analysis to confirm the specificity of amplification and the absence of primer dimer.

\section{Western blotting}

Cell lysates were prepared in buffer containing $62.5 \mathrm{mM}$ Tris$\mathrm{HCl}(\mathrm{pH} 6.8), 10 \%$ glycerol, $2 \%$ SDS, and $50 \mathrm{mM}$ dithiothreitol. Protein concentrations were determined using the Bio-Rad Protein Assay (Bio-Rad Laboratories). Total proteins were separated by SDS-PAGE and transferred to PVDF membranes. CITED2 was detected using anti-CITED2 antibody (ab108345; Abcam) at a dilution of 1:500.

\section{RNA-seq analysis}

Transcriptomic profiles in control shRNA-treated Rcho-1 TS cells and Cited2 shRNA knockdown Rcho-1 TS cells $(n=3$ each) were performed using RNA-seq analysis. cDNA libraries from total RNA samples were prepared with Illumina TruSeq RNA sample preparation kits (Illumina, San Diego, CA, USA). Five hundred nanograms of total RNA were used as input. Poly-A-containing RNAs were purified with oligo-dT-coated magnetic beads. RNA fragmentation, first- and second-strand cDNA synthesis, end repair, adaptor ligation, and PCR amplification were performed according to the manufacturer's recommendations. The cDNA libraries were validated for RNA integrity using an Agilent 2100 Bioanalyzer (Agilent Technologies) before sequencing.

cDNA libraries were clustered onto a TruSeq paired-end flow cell and sequenced (100 bp-end reads) using a TruSeq 200 Cycle SBS Kit (Illumina). Samples were run on an Illumina HiSeq2000 sequencer located at the University of Kansas Medical Center Genome Sequencing Facility and sequenced in parallel with other samples to ensure the data generated for each run were accurately calibrated during data analysis. Following generation of sequencing images, the pixel-level raw data collection, image analysis, and base calling were performed by Real-Time Analysis Software (Illumina). The base call files (*.bcl) were converted to *.qseq files by Illumina's $\mathrm{BCL}$ Converter, and the *.qseq files were subsequently converted to *.fastq files for downstream analysis. Reads from * fastq files were mapped to the rat reference genome (Ensembl Rnor_5.0.78) using CLC Bio Genomics Workbench 7.0 (CLC Bio, Aarhus, Denmark). The mRNA abundance was expressed in reads per kilobase of exon per million reads mapped. Statistical significance was calculated by empirical analysis of digital gene expression in the CLC Bio Genomics Workbench. A corrected false discovery rate (FDR) of 0.05 was used as a cutoff for significant differential expression (control vs Cited2-knockdown). Functional patterns of transcript expression were further analyzed using Ingenuity Pathway Analysis (Qiagen) and Database for Annotation, Visualization and Integrated Discovery (DAVID v6.7; https:// david.ncifcrf.gov/). Results from the RNA-seq analysis were validated using qRT-PCR. Primer sets for the qRT-PCR are shown in Table 1.

\section{Statistical analysis}

Values are expressed as the mean \pm S.E.M. Comparisons between more than two groups were made using one-way ANOVA following log10 transformation of the raw data and multiple comparisons were done using Dunnett's post hoc test. The procedure

Table 1 Primers for qRT-PCR analysis.

\begin{tabular}{|c|c|c|c|}
\hline Target gene & Forward primer & Reverse primer & Accession number \\
\hline Apoa4 & ACAGCTCAATACССТСТTCCAG & GGCTCAСTTTGTTGGCATGG & NM_012737 \\
\hline Ass 1 & AAAAAGGGGTCCСTGTGAAG & ATGAGCGTGGTAAAGGATGG & NM_013157 \\
\hline Cited2 & GAAGGACTGGAAATGGCAGA & GCGCCGTAGTGTATGTGCT & NM_053698 \\
\hline$E g \ln 3$ & СТССТATGCCACCAGGTACG & ACAAGGTAGGGAGCCAAACG & NM_019371 \\
\hline F3 & GTGTCCTGGGAGAAACACTCAT & CCAGCAGAGGTCTCGGTAAC & NM_013057 \\
\hline$/ / 1 r 2$ & CATGGGAGATGCAGGCTATT & TACCAGTTCCCAGGAACACC & NM_053953 \\
\hline Krt15 & GATCCAGGGGCTCATTACCG & AGCAGCCATCTTAGCATCCTG & NM_001004022 \\
\hline Mest & CAAGCCGAGACCACATCAGT & GTGAGACGGCCAGAACGATT & NM_001009617 \\
\hline Mmp12 & ACATGAAGCGTGCGGATGTA & AGGAACAGGTTTGTGCCTTGA & NM_053963 \\
\hline Prl8a5 & ССTCCGGAAGCATTTAACAG & GATTTGGGTTTTGCACGATT & NM_173110 \\
\hline Prl8a9 & GGCACATTCСTGATGCTTGC & ССТAATCAGTTTTGAGTTAAGAGCC & XM_006253905 \\
\hline Ptprk & ACTACATCGATGGCTACCAGAG & AGCATTTCACCCGACCAACT & XM_008758616 \\
\hline Pxdc1 & CAACCCAGCTTTCAAAGTCC & CTGGGTCATCACCATCTTCC & NM_001025719 \\
\hline Thbd & САCTGGACTCGGGAAGTGAC & TGGTAGCCTGTTTCGCACAT & NM_031771 \\
\hline Timp3 & ACAGACGCCAGAGTCTCCTA & ACСTCAAGTCTGTCCGGGTA & NM_012886 \\
\hline Top2a & CAGCGTGTTGAGCCTGAATG & TAACTTGGGAGCATGGGCAG & NM_022183 \\
\hline Tpbpa & TGAATTGCAAGAGCAGAAGGGTA & CATCGCCAAGTGACTGTGCT & NM_172073 \\
\hline 185 rRNA & GCAATTATTCCССАTGAACG & GGCСTCACTAAACCATCCAA & NR_046237 \\
\hline
\end{tabular}


A

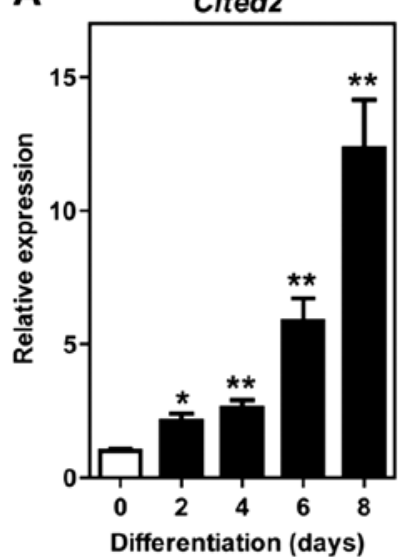

B

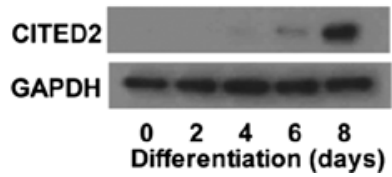

C

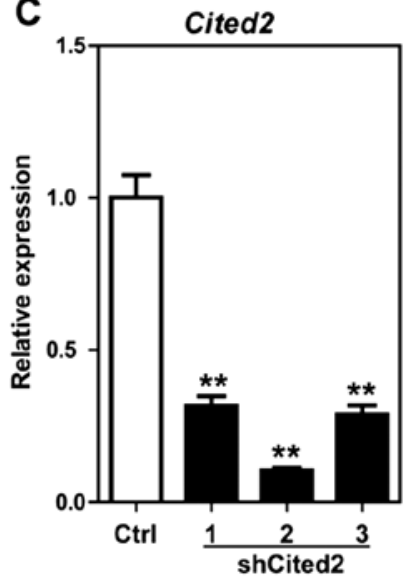

D

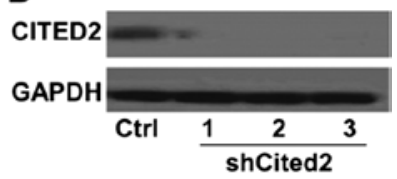

Figure 1 CITED2 expression in Rcho-1 TS cells. Differentiationstimulated induction of Cited2 transcript (A) and protein (B) during Rcho-1 TS cell differentiation. Effectiveness of CITED2 shRNAs in the inhibition of CITED2 mRNA (C) and protein (D) in differentiating Rcho-1 TS cells. Rcho-1 TS cells were stably infected with lentiviral vectors containing an shRNA to a control (Ctrl) sequence or three different and independent shRNAs to Cited2 (shCited2-1, shCited2-2, and shCited2-3) and differentiated for 8 days. Cited 2 sequences targeted by each shRNA are provided in the 'Materials and methods' section. The effectiveness of the Cited 2 shRNAs was compared with an shRNA to a Ctrl sequence, which does not recognize any known mammalian transcript. Statistical comparisons were made using one-way ANOVA and multiple comparisons were done using Dunnett's post hoc test. ${ }^{*} P<0.01$ and ${ }^{* *} P<0.001$.

for analyzing the RNA-seq data is described in the preceding paragraph.

\section{Results}

CITED2 is a transcriptional co-regulator implicated in the regulation of placentation (Withington et al. 2006, Moreau et al. 2014). We sought to gain insight into the role of CITED2 in trophoblast development using a loss-of-function approach in rat Rcho-1 TS cells.

\section{Cited2 expression in differentiating trophoblast cells}

Initially, we profiled the expression of CITED2 transcript and protein in stem and differentiating Rcho-1 TS cells using qRT-PCR and western blotting respectively. Both CITED2 mRNA and protein exhibited a robust increase in expression as Rcho-1 TS cells underwent differentiation (Fig. 1A and B). These observations are consistent with earlier findings correlating Cited 2 expression with trophoblast differentiation (Kent et al. 2010) and directed us to examine the developmental consequences of Cited2-knockdown in differentiating Rcho-1 TS cells.
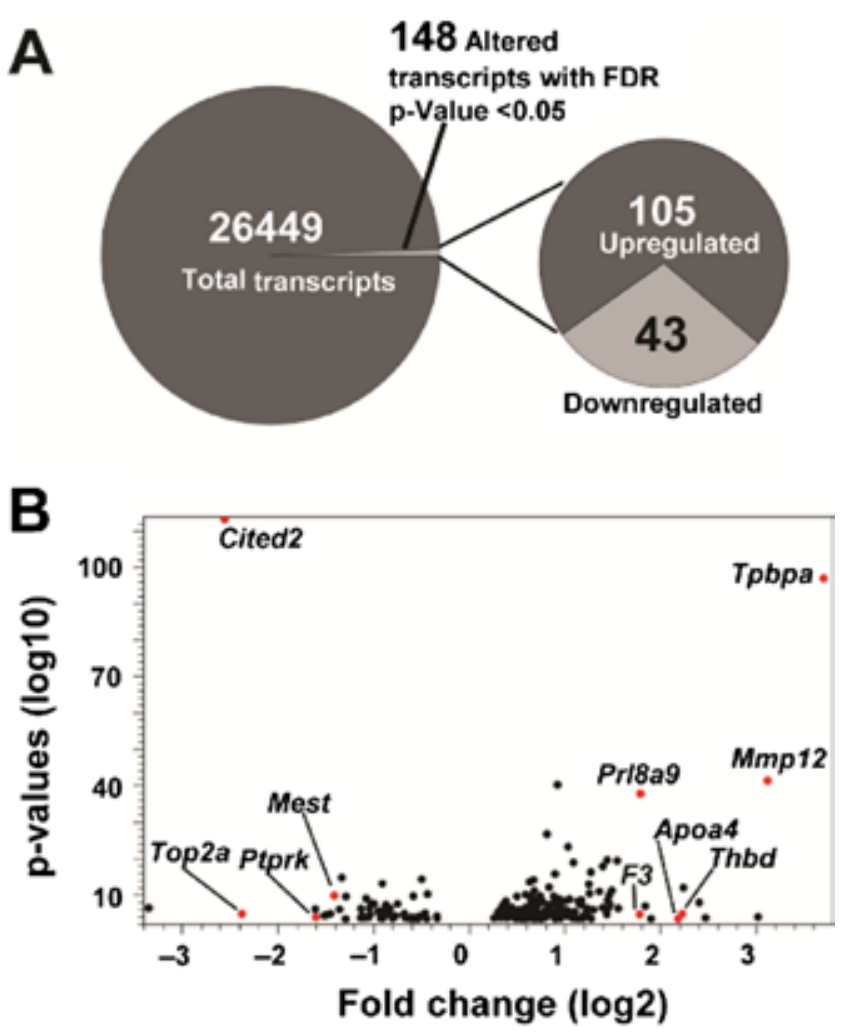

Figure 2 Analysis of transcripts affected by Cited2-knockdown in trophoblast cells. RNA-seq was performed on Rcho-1 TS cells expressing either control shRNA or an shRNA to Cited2 (shCited2-2) under differentiating conditions. (A) Pie chart showing the number of transcripts with altered expression levels in Rcho-1 TS cells expressing either control shRNA or shCited2-2. (B) Volcano plot of differentially expressed transcripts. The $x$-axis shows $\log 2$ fold changes in expression and the $y$-axis shows corresponding $\log 10 P$ values. Some of the transcripts altered greater than or equal to two-fold $(P<0.05)$ in cells expressing shCited2-2 are highlighted in red.

\section{Identification of CITED2 downstream targets in differentiating trophoblast cells}

We utilized an shRNA approach to inhibit the expression of CITED2 in Rcho-1 TS cells and RNA-seq to characterize the transcriptome of the manipulated cells. Rcho-1 TS cells were stably infected with lentiviral constructs containing shRNAs specifically targeting three different and independent sequences within Cited2 termed shCited2-1, shCited2-2, or shCited2-3 or a control shRNA and exposed to differentiation culture conditions. CITED2 shRNAs effectively inhibited the expression of the differentiation-dependent up-regulation of CITED2 mRNA and protein (Fig. 1C and D). Disruption of CITED2 expression did not interfere with trophoblast cell proliferation or morphological indices of trophoblast giant cell formation. It is important to appreciate that trophoblast cell differentiation is more than the formation of trophoblast giant cells. Trophoblast giant cells can possess distinct phenotypes (Simmons et al. 2007) and other distinct differentiated trophoblast cell lineages can arise from TS cells (Gardner \& Beddington 1988, Soares 
Table 2 Selected transcripts identified by RNA-seq in differentiating control and Cited 2 shRNA-treated Rcho-1 TS cells.

\begin{tabular}{|c|c|c|c|c|}
\hline Gene description & Gene symbol & Biological properties & Chromosome & $\begin{array}{l}\text { Cited } 2 \text { shRNA/ } \\
\text { control shRNA }\end{array}$ \\
\hline Trophoblast-specific protein alpha & Tpbpa & Related to cysteine-type endoprotease & 17 & 12.1 \\
\hline Matrix metallopeptidase 12 & Mmp12 & Metalloelastase, ECM, coagulation & 8 & 8.1 \\
\hline Egl-9 family hypoxia-inducible factor 3 & Egln3 & Prolyl hydroxylase, hypoxia signaling & 6 & 5.5 \\
\hline Prolactin family 8 , subfamily a, member 5 & Prloa5 & Cytokine, hormone & 17 & 5.0 \\
\hline Thrombomodulin & Thbd & Thrombin receptor, coagulation & 3 & 4.5 \\
\hline Apolipoprotein A-IV & Ароа4 & Lipid metabolism & 8 & 4.4 \\
\hline TIMP metalloproteinase inhibitor 3 & Timp3 & $\begin{array}{l}\text { Inhibitor of matrix metallopeptidases, } \\
\text { ECM }\end{array}$ & 7 & 3.6 \\
\hline Keratin 15 & Krt15 & Intermediate filaments, epithelial cells & 10 & 3.3 \\
\hline Coagulation factor 3 & F3 & Coagulation & 2 & 3.2 \\
\hline Prolactin family 8 , subfamily a, member 9 & Prl8a9 & Cytokine, hormone & 17 & 3.2 \\
\hline Interleukin 1 receptor, type II & $1 / 1 r 2$ & Decoy receptor for IL1 ligands & 9 & 2.6 \\
\hline PX domain containing 1 & Pxdc1 & Phosphatidylinositol binding & 17 & 2.5 \\
\hline Argininosuccinate synthase 1 & Ass 1 & Arginine biosynthetic pathway & 3 & 0.37 \\
\hline Mesoderm specific transcript & Mest & $\begin{array}{l}\text { Hydrolase superfamily, imprinted, } \\
\text { developmentally regulated }\end{array}$ & 4 & 0.34 \\
\hline Protein tyrosine phosphatase, receptor type K & Ptprk & $\begin{array}{l}\text { Signaling pathway controlling cell-cell } \\
\text { adhesion, growth control, and invasion }\end{array}$ & 1 & 0.30 \\
\hline Topoisomerase (DNA) II alpha & Top2a & $\begin{array}{l}\text { Nuclear protein regulating chromosome } \\
\text { dynamics }\end{array}$ & 10 & 0.17 \\
\hline $\begin{array}{l}\text { Cbp/p300-interacting transactivator, with } \\
\text { Glu/Asp-rich carboxy-terminal domain } 2\end{array}$ & Cited2 & Transcription co-regulator & 1 & 0.16 \\
\hline
\end{tabular}

ECM, extracellular matrix.

et al. 1996, 2012, Simmons \& Cross 2005). Thus, RNAseq was performed on Rcho-1 TS cells stably expressing control shRNA vs CITED2 shRNA (shCited2-2) on day 8 of differentiation to gain additional insights into the role of CITED2 in the regulation of trophoblast cell differentiation. Results from the RNA-seq analysis are deposited in the Gene Expression Omnibus (accession no. GSE74748). A total of 148 known transcripts (105 up-regulated vs 43 down-regulated) exhibited a significant change in expression (FDR, $P<0.05)$ in control vs CITED2 shRNA cells (Fig. 2A and B). Table 2 includes a list of selected up-regulated and down-regulated transcripts. Canonical pathways sensitive to CITED2 disruption included signal transduction cascades (e.g., ERK/MAPK, peroxisome proliferator-activated receptor, eukaryotic initiation factor 2, paxillin, integrin-linked kinase, phospholipase C, and integrin) and processes associated with leukocyte extravasation and phagocytosis (Table 3). Additional insights from the pathway analyses were not evident. qRTPCR was used to validate expression of a set of selected up-regulated and down-regulated transcripts (Fig. 3). Several features characterized subsets of up-regulated transcripts: i) transcripts expressed by non-trophoblast giant cell lineages of differentiated trophoblast cells (Tpbpa, Mmp12, Prl8a5, and Pr/8a9); ii) known hypoxia/ HIF-responsive transcripts (Tpbpa, Mmp12, and Eg/n3); and iii) transcripts encoding proteins associated with coagulation/thrombosis (Mmp12, F3, and Thbd). A prominent feature associated with several down-regulated transcripts (Top2a, Ptprk, and Mest) is their known linkage

Table 3 Analysis of pathways affected for CITED2 disruption in differentiating Rcho-1 TS cells.

\begin{tabular}{|c|c|c|c|c|}
\hline Canonical pathways & $-\log (P$ value $)$ & Ratio & Z-score & Molecules \\
\hline ERK/MAPK signaling & 1.44 & $3.09 \times 10^{-2}$ & -0.45 & $\begin{array}{l}\text { ITGB1, FOS, H3F3A/H3F3B, PRKCl, and } \\
\text { SOS1 }\end{array}$ \\
\hline PPAR signaling & 2.53 & $5.75 \times 10^{-2}$ & -1.34 & IL1R2, FOS, HSP90B1, SOS1, and CITED2 \\
\hline EIF2 signaling & 3.68 & $5.59 \times 10^{-2}$ & 1.34 & $\begin{array}{l}\text { PABPC1, RPL14, RPL22, SOS1, RPL17, } \\
\text { RPL10, EIF4A2, and RPS25 }\end{array}$ \\
\hline Leukocyte extravasation & 2.56 & $4.19 \times 10^{-2}$ & 1.63 & $\begin{array}{l}\text { ITGB1, TIMP3, PRKCI, CDH5, MMP12, } \\
\text { ACTG1, and ACTN1 }\end{array}$ \\
\hline Paxillin signaling & 4.17 & $7.78 \times 10^{-2}$ & 1.63 & $\begin{array}{l}\text { ITGB1, SOS1, ARHGEF6, ITGAV, PTPN12, } \\
\text { ACTG1, and ACTN1 }\end{array}$ \\
\hline $\begin{array}{l}\text { Fc } \gamma \text { receptor-mediated phagocytosis in } \\
\text { macrophages and monocytes }\end{array}$ & 1.78 & $4.60 \times 10^{-2}$ & 2.00 & HMOX1, PRKCl, ARPC2, and ACTG1 \\
\hline ILK signaling & 3.39 & $5.06 \times 10^{-2}$ & 2.12 & $\begin{array}{l}\text { ITGB1, FOS, FN1, ARHGEF6, FERMT2, } \\
\text { TMSB10/TMSB4X, ACTG1, and ACTN1 }\end{array}$ \\
\hline Phospholipase C signaling & 1.64 & $3.08 \times 10^{-2}$ & 2.24 & $\begin{array}{l}\text { ITGB1, HMOX1, PRKCI, AHNAK, SOS1, } \\
\text { and ARHGEF6 }\end{array}$ \\
\hline Integrin signaling & 2.39 & $3.91 \times 10^{-2}$ & 2.65 & $\begin{array}{l}\text { ITGB1, ASAP1, ARPC2, SOS1, ITGAV, } \\
\text { ACTG1, and ACTN1 }\end{array}$ \\
\hline
\end{tabular}

PPAR, peroxisome proliferator-activated receptor; EIF2, eukaryotic initiation factor 2; ILK, integrin-linked kinase. 

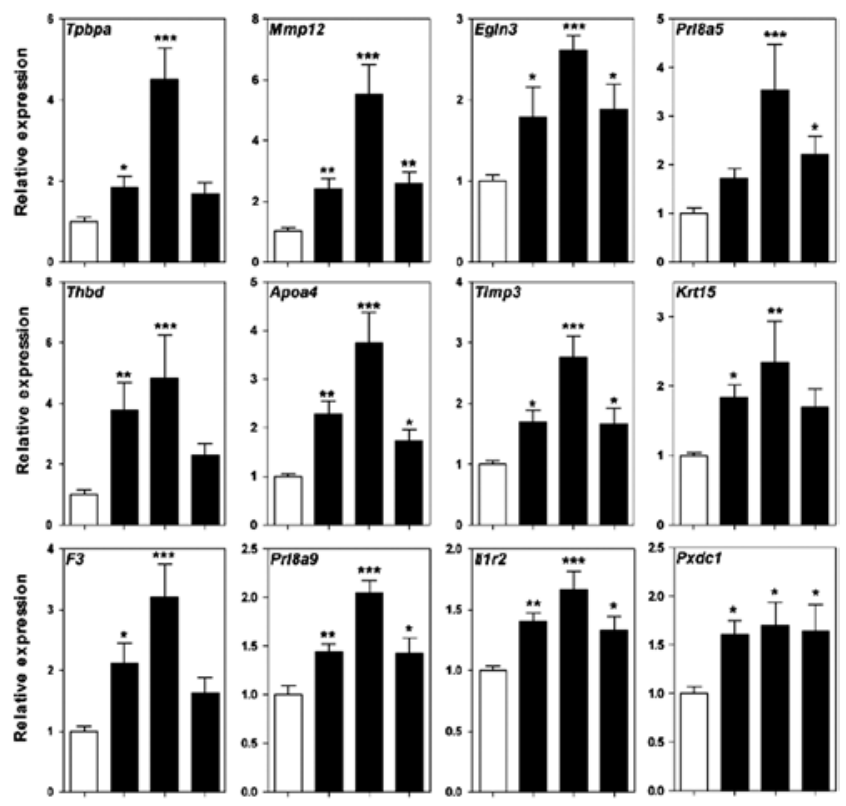

${ }^{25}$ Pxder
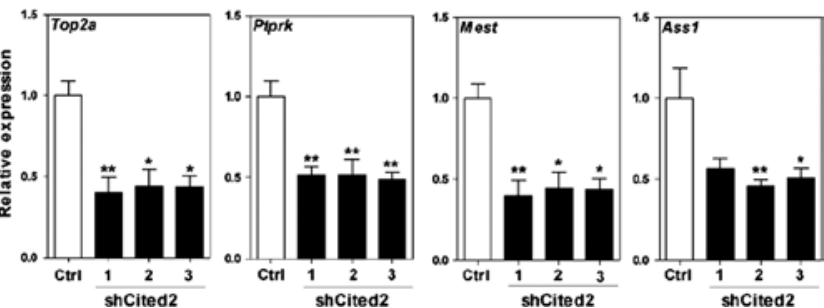

Figure 3 qRT-PCR validation of RNA-seq analysis. Selected transcripts affected by Cited2-knockdown in the RNA-seq analysis were examined by qRT-PCR. qRT-PCR measurements from Rcho- 1 TS cells infected with lentiviral vectors containing an shRNA to a control (Ctrl) sequence or three different and independent shRNAs to Cited 2 (shCited2-1, shCited2-2, and shCited2-3) were performed. Cited2 sequences targeted by each shRNA are provided in the 'Materials and methods' section. Statistical comparisons were made using one-way ANOVA and multiple comparisons were done using Dunnett's post hoc test. ${ }^{*} P<0.05,{ }^{* *} P<0.01$, and ${ }^{* * *} P<0.001$.

with the Rcho-1 TS cell stem state (Kent et al. 2010). Mitogen removal promotes differentiation of Rcho-1 TS cells and is also compatible with the survival of quiescent TS cells, which can be revived by reintroduction of a mitogenic stimulus (Sahgal et al. 2006). Collectively, our findings indicate that CITED2 may restrain expansion of TS cells in the stem state, promote TS cell quiescence, and/or direct trophoblast cell differentiation.

\section{Discussion}

CITED2 is an established regulator of cell growth and differentiation and has been implicated in a broad range of developmental events, including neural tube, heart, lung, liver, hematopoietic, gonad, adrenal, and placental morphogenesis (Bamforth et al. 2001, Barbera et al. 2002, Yin et al. 2002, Withington et al. 2006, Qu et al. 2007, Val et al. 2007, Xu et al. 2008, Combes et al. 2010, Du \& Yang 2013). In this report, we provide insight into the modulatory actions of CITED2 on trophoblast cell differentiation.
A null mutation at the Cited 2 locus of the mouse leads to defects in placentation (Withington et al. 2006, Moreau et al. 2014). Cited2-null placentas are smaller than those from WT littermates with a profound disruption in the development of the junctional zone (Withington et al. 2006). Each differentiated trophoblast cell lineage is present in the Cited2-null placenta; however, the absence of CITED2 affects the organization and function of the differentiated trophoblast cell lineages. Differentiating Rcho-1 TS cells exhibit many features of junctional zone trophoblast cell development (Soares et al. 1996). Some of the most prominent effects of disrupting CITED2 in differentiating Rcho-1 TS cells was up-regulation of Tpbpa, Mmp12, Timp3, and Eg/n3 expression. Tpbpa expression identifies a progenitor population of trophoblast cells within the developing junctional zone possessing the capacity to differentiate into spongiotrophoblast, glycogen cells, invasive trophoblast cells, and subsets of trophoblast giant cells (Hu \& Cross 2011). MMP12 localizes to invasive endovascular trophoblast lining uterine spiral arterioles (Harris et al. 2010, D Chakraborty and M J Soares, unpublished observations) and is viewed as a contributor to pregnancy-dependent structural changes associated with these vessels that are critical for hemochorial placentation (Harris et al. 2010). MMP12 is a member of the matrix metalloproteinase family and among its targets is elastin, a prominent constituent of the arterial vasculature (Van Doren 2015). Paradoxically, the transcript for TIMP3, a broad-spectrum inhibitor of MMPs (Brew \& Nagase 2010), is also up-regulated by Cited2-knockdown, reflecting a level of complexity to CITED2 action in differentiating trophoblast cells. Tpbpa and Mmp 12 are known for hypoxia- and HIF-regulated genes in rat TS cells (Chakraborty et al. 2011). Eg/n3 is a hypoxia/HIF-responsive transcript and encodes for a negative modulator of HIF activities (Lee \& Percy 2011). Even though Rcho-1 TS cells were not cultured in hypoxic conditions in the present work, there is some evidence for the involvement of HIF signaling in TS cell differentiation exposed to atmospheric conditions (Maltepe et al. 2005). Thus up-regulation of Tpbpa, Mmp12, and EgIn3 in the present work may reflect removal of CITED2 antagonism of HIF actions.

CITED2-knockdown also led to an increase in the expression of trophoblast cell transcripts possessing ties to blood coagulation (Mmp12, F3, and Thbd). MMP12 has both pro- and anti-coagulant actions via inactivation of tissue factor pathway inhibitor (Belaaouaj et al. 2000) and the inhibition of circulating fibrinogen levels (Motterle et al. 2012) respectively. F3 (also known as tissue factor) is a pro-coagulant (Pawlinski et al. 2004) and THBD is an inhibitor of blood coagulation (Isermann et al. 2001, 2003, Weiler 2004). Thus, CITED2 negatively regulates multiple transcripts encoding regulatory components of the blood coagulation pathway with apparently opposing outcomes. 
Trophoblast differentiation is a multi-lineage process (Gardner \& Beddington 1988, Simmons \& Cross 2005, Soares et al. 2012). In vitro differentiation of Rcho-1 TS cells favors trophoblast giant cell differentiation (Faria \& Soares 1991, Sahgal et al. 2006, Kent et al. 2010). Transcripts exhibiting some of the most dramatic changes following CITED2 manipulation are characteristic of trophoblast lineages other than the trophoblast giant cell lineage. Thus, at least in the context of differentiating Rcho-1 TS cells, CITED2 appears to guide/restrict the specialization of specific differentiated trophoblast cell populations, potentially favoring trophoblast giant cell development and inhibiting the development of Tpbpapositive progenitors and their descendants.

A key mechanism of action of CITED2 is its modulation of transcription factor interactions with the histone acetyl transferases, CREBBP and EP300 (Bhattacharya \& Ratcliffe 2003, Du \& Yang 2013). These histone acetyl transferases govern gene activation of numerous transcription factors (Vo \& Goodman 2001, Bedford et al. 2010), including many that have been implicated in regulating trophoblast cell differentiation (GATA2, GATA3, AP-1, TFAP2C, ETS2, HIF1, PPARG, and SATB1; Soares et al. 2014, Soncin et al. 2015). Thus, CITED2 has the potential to modulate a wide spectrum of biological processes associated with trophoblast development. However, at this juncture, only two known modulators of trophoblast development, HIF1 and TFAP2C, have been directly connected to CITED2 (Bhattacharya et al. 1999, Bamforth et al. 2001, Yin et al. 2002, Braganca et al. 2003, Freedman et al. 2003). The precise mechanism(s) underlying the effects of CITED2 on the differentiated trophoblast cell transcriptome remains to be determined.

\section{Declaration of interest}

The authors declare that there is no conflict of interest that could be perceived as prejudicing the impartiality of the research reported.

\section{Funding}

This work was supported by the National Institutes of Health (HD020676 and HD079363).

\section{Acknowledgements}

The authors thank S McClure for administrative assistance.

\section{References}

Adelman DM, Gertsenstein M, Nagy A, Simon MC \& Maltepe E 2000 Placental cell fates are regulated in vivo by HIF-mediated hypoxia responses. Genes and Development 14 3191-3203. (doi:10.1101/gad.853700)

Ain R, Canham LN \& Soares MJ 2003 Gestation stage-dependent intrauterine trophoblast cell invasion in the rat and mouse: novel endocrine phenotype and regulation. Developmental Biology $260176-$ 190. (doi:10.1016/S0012-1606(03)00210-0)

Amoroso EC 1968 The evolution of viviparity. Proceedings of the Royal Society of Medicine 61 1188-1200.
Asanoma K, Kubota K, Chakraborty D, Renaud SJ, Wake N, Fukushima K, Soares MJ \& Rumi MA 2012 SATB homeobox proteins regulate trophoblast stem cell renewal and differentiation. Journal of Biological Chemistry 287 2257-2268. (doi:10.1074/jbc.M111.287128)

Bamforth SD, Bragança J, Eloranta JJ, Murdoch JN, Marques FI, Kranc KR, Farza H, Henderson DJ, Hurst HC \& Bhattacharya S 2001 Cardiac malformations, adrenal agenesis, neural crest defects and exencephaly in mice lacking Cited2, a new Tfap2 co-activator. Nature Genetics 29 469-474. (doi:10.1038/ng768)

Barbera JP, Rodriguez TA, Greene ND, Weninger WJ, Simeone A, Copp AJ, Beddington RS \& Dunwoodie S 2002 Folic acid prevents exencephaly in Cited2 deficient mice. Human Molecular Genetics 11 283-293. (doi:10.1093/hmg/11.3.283)

Bedford DC, Kasper LH, Fukuyama T \& Brindle PK 2010 Target gene context influences the transcriptional requirement for the KAT3 family of CBP and p300 histone acetyltransferases. Epigenetics 5 9-15. (doi:10.4161/epi.5.1.10449)

Belaaouaj AA, Li A, Wun T-C, Welgus HG \& Shapiro SD 2000 Matrix metalloproteinases cleave tissue factor pathway inhibitor. Effects on coagulation. Journal of Biological Chemistry 275 27123-27128.

Bhattacharya S \& Ratcliffe PJ 2003 ExCITED about HIF. Nature Structural Biology 10 501-503. (doi:10.1371/journal.pmed.1001973)

Bhattacharya S, Michels CL, Leung MK, Arany ZP, Kung AL \& Livingston DM 1999 Functional role of p35srj, a novel p300/CBP binding protein, during transactivation by HIF-1. Genes and Development 13 64-75. (doi:10.1101/gad.13.1.64)

Bragança J, Eloranta JJ, Bamforth SD, Ibbitt JC, Hurst HC \& Bhattacharya S 2003 Physical and functional interactions among AP-2 transcription factors, p300/CREB-binding protein, and CITED2. Journal of Biological Chemistry 278 16021-16029. (doi:10.1074/jbc.M208144200)

Brew K \& Nagase H 2010 The tissue inhibitors of metalloproteinases (TIMPs): an ancient family with structural and functional diversity. Biochimica et Biophysica Acta 1803 55-71. (doi:10.1016/j.bbamcr.2010.01.003)

Caniggia I, Mostachfi H, Winter J, Gassmann M, Lye SJ, Kuliszewski M \& Post M 2000 Hypoxia-inducible factor-1 mediates the biological effects of oxygen on human trophoblast differentiation through TGF $\beta 3$. Journal of Clinical Investigation 105 577-587. (doi:10.1172/JCl8316)

Chakraborty D, Rumi MAK, Konno T \& Soares MJ 2011 Natural killer cells direct hemochorial placentation by regulating HIF-dependent trophoblast lineage decisions. PNAS 108 16295-16300. (doi:10.1073/pnas.1109478108)

Combes AN, Spiller CM, Harley VR, Sinclair AH, Dunwoodie SL, Wilhelm D \& Koopman P 2010 Gonadal defects in Cited2-mutant mice indicate a role for SF1 in both testis and ovary differentiation. International Journal of Developmental Biology 54 683-689. (doi:10.1387/ijdb.092920ac)

Cross JC, Werb Z \& Fisher SJ 1994 Implantation and the placenta: key pieces of the development puzzle. Science 266 1508-1518. (doi:10.1095/biolreprod60.2.312)

Dilworth MR \& Sibley CP 2013 Transport across the placenta of mice and women. Placenta 34 (Supplement) S34-S39. (doi:10.1016/j. placenta.2012.10.011)

Du J \& Yang YC 2013 Cited2 in hematopoietic stem cell function. Current Opinion in Hematology 20301-307. (doi:10.1371/journal.pone.0151371)

Dunwoodie SL 2009 The role of hypoxia in development of the mammalian embryo. Developmental Cell 17 755-773. (doi:10.1016/j. devcel.2009.11.008)

Faria TN \& Soares MJ 1991 Trophoblast cell differentiation: establishment, characterization, and modulation of a rat trophoblast cell line expressing members of the placental prolactin family. Endocrinology 129 28952906. (doi:10.1590/1806-9282.60.04.019)

Freedman SJ, Sun ZY, Kung AL, France DS, Wagner G \& Eck MJ 2003 Structural basis for negative regulation of hypoxia-inducible factor- $1 \alpha$ by CITED2. Nature Structural Biology 10 504-512. (doi:10.1038/nsb936)

Gardner RL \& Beddington RS 1988 Multi-lineage 'stem' cells in the mammalian embryo. Journal of Cell Science $\mathbf{1 0}$ (Supplement) 11-27. (doi:10.1242/jcs.1988.Supplement_10.2)

Georgiades P, Ferguson-Smith AC \& Burton GJ 2002 Comparative developmental anatomy of the murine and human definitive placentae. Placenta 23 3-19. (doi:10.1053/plac.2001.0738)

Harris LK, Smith SD, Keogh RJ, Jones RL, Baker PN, Knofler M, Cartwright JE, Whitley GSJ \& Aplin JD 2010 Trophoblast- and vascular smooth muscle cell-derived MMP-12 mediates elastolysis during uterine spiral artery remodeling. American Journal of Pathology 177 2103-2115. (doi:10.2353/ajpath.2010.100182) 
Hu D \& Cross JC 2011 Ablation of Tpbpa-positive trophoblast precursors leads to defects in maternal artery remodeling in the mouse placenta. Developmental Biology 358 231-239. (doi:10.1016/j.ydbio.2011.07.036)

Isermann B, Hendrickson SB, Hutley K, Wing M \& Weiler H 2001 Tissuerestricted expression of thrombomodulin in the placenta rescues thrombomodulin-deficient mice from early lethality and reveals a secondary developmental block. Development 128 827-838.

Isermann B, Sood R, Pawlinski R, Zogg M, Kalloway S, Degen JL, Mackman N \& Weiler H 2003 The thrombomodulin-protein C system is essential for the maintenance of pregnancy. Nature Medicine $\mathbf{9} 331$ 337. (doi:10.1038/nm825)

Kent LN, Konno T \& Soares MJ 2010 Phosphatidylinositol 3 kinase modulation of trophoblast cell differentiation. BMC Developmental Biology 10 97. (doi:10.1186/1471-213X-10-97)

Kent LN, Rumi MA, Kubota K, Lee DS \& Soares MJ 2011 FOSL1 is integral to establishing the maternal-fetal interface. Molecular and Cellular Biology 31 4801-4813. (doi:10.1128/MCB.05780-11)

Knipp GT, Audus KL \& Soares MJ 1999 Nutrient transport across the placenta. Advanced Drug Delivery Reviews 38 41-58. (doi:10.1016/ S0169-409X(99)00005-8)

Kubota K, Kent LN, Rumi MAK, Roby KF \& Soares MJ 2015 Dynamic regulation of AP-1 transcriptional complexes directs trophoblast differentiation. Molecular and Cellular Biology 35 3163-3177. (doi:10.1128/MCB.00118-15)

Kuckenberg P, Kubaczka C \& Schorle H 2012 The role of transcription factor Tcfap2c/TFAP2C in trophectoderm development. Reproductive Biomedicine Online 25 12-20. (doi:10.1016/j.stem.2015.08.005)

Lee FS \& Percy MJ 2011 The HIF pathway and erythrocytosis. Annual Review of Pathology 6 165-192. (doi:10.1146/annurev-pathol-011110-130321)

Maltepe E, Krampitz GW, Okazaki KM, Red-Horse K, Mak W, Simon MC \& Fisher SJ 2005 Hypoxia-inducible factor-dependent histone deacetylase activity determines stem cell fate in the placenta. Development 132 3393-3403. (doi:10.1242/dev.01923)

Moreau JL, Artap ST, Shi H, Chapman G, Leone G, Sparrow DB \& Dunwoodie SL 2014 Cited2 is required in trophoblasts for correct placental capillary patterning. Developmental Biology 392 62-79. (doi:10.1016/j.ydbio.2014.04.023)

Motterle A, Xiao Q, Kiechl S, Pender SLF, Morris GE, Willeit J, Caulfield MJ \& Ye S 2012 Influence of matrix metalloproteinase-12 on fibrinogen level. Atherosclerosis 220 351-354. (doi:10.1016/j. atherosclerosis.2011.11.003)

Pawlinski R, Pedersen B, Erlich J \& Mackman N 2004 Role of tissue factor in haemostasis, thrombosis, angiogenesis and inflammation: lessons from low tissue factor mice. Thrombosis and Haemostasis 92 444-450.

Pijnenborg R, Vercruysse L \& Hanssens M 2006 The uterine spiral arteries in human pregnancy: facts and controversies. Placenta 27 939-958. (doi:10.1016/j.placenta.2013.01.002)

Qu X, Lam E, Doughman Y-Q, Chen Y, Chou Y-T, Lam M, Turakhia M, Dunwoodie SL, Watanabe M, Xu B et al. 2007 Cited2, a coactivator of HNF4a, is essential for liver development. EMBO Journal 26 44454456. (doi:10.1038/sj.emboj.7601883)

Renaud SJ, Kubota K, Rumi MA \& Soares MJ 2014 The FOS transcription factor family differentially controls trophoblast migration and invasion. Journal of Biological Chemistry 289 5025-5039. (doi:10.1074/jbc. M113.523746)

Roberts RM \& Fisher SJ 2011 Trophoblast stem cells. Biology of Reproduction 84 412-421. (doi:10.1095/biolreprod.110.088724)

Sahgal N, Canham LN, Canham B \& Soares MJ 2006 Rcho-1 trophoblast stem cells: a model system for studying trophoblast cell differentiation. Methods in Molecular Medicine 121 159-178.

Schorpp-Kistner M, Wang ZQ, Angel P \& Wagner EF 1999 JunB is essential for mammalian placentation. EMBO Journal 18 934-948. (doi:10.1093/ emboj/18.4.934)

Schreiber M, Wang ZQ, Jochum W, Fetka I, Elliott C \& Wagner EF 2000 Placental vascularization requires the AP-1 component fra1. Development 127 4937-4948.

Semenza GL 2010 Oxygen homeostasis. Wiley Interdisciplinary Reviews. Systems Biology and Medicine 2 336-361. (doi:10.1002/wsbm.69)

Sibley C, Glazier J \& D'Souza S 1997 Placental transporter activity and expression in relation to fetal growth. Experimental Physiology 82389 402. (doi:10.1113/expphysiol.1997.sp004034)
Simmons DG \& Cross JC 2005 Determinants of trophoblast lineage and cell subtype specification in the mouse placenta. Developmental Biology 284 12-24. (doi:10.1038/cr.2015.100)

Simmons DG, Fortier AL \& Cross JC 2007 Diverse subtypes and developmental origins of trophoblast giant cells in the mouse placenta. Developmental Biology 304 567-578. (doi:10.1016/j. ydbio.2007.01.009)

Simon MC \& Keith B 2008 The role of oxygen availability in embryonic development and stem cell function. Nature Reviews. Molecular Cell Biology 9 285-296. (doi:10.1038/nrm2354)

Soares MJ 2004 The prolactin and growth hormone families: pregnancyspecific hormones/cytokines at the maternal-fetal interface. Reproductive Biology and Endocrinology 51.

Soares MJ, Chapman BM, Rasmussen CA, Dai G, Kamei T \& Orwig KE 1996 Differentiation of trophoblast endocrine cells. Placenta 17 277289. (doi:10.1016/S0143-4004(96)90051-X)

Soares MJ, Chakraborty D, Rumi MA, Konno T \& Renaud SJ 2012 Rat placentation: an experimental model for investigating the hemochorial maternal-fetal interface. Placenta 33 233-243. (doi:10.1262/jrd.2011-039)

Soares MJ, Chakraborty D, Kubota K, Renaud SJ \& Rumi MA 2014 Adaptive mechanisms controlling uterine spiral artery remodeling during the establishment of pregnancy. International Journal of Developmental Biology 58 247-259. (doi:10.1387/ijdb.140083ms)

Soncin F, Natale D \& Parast MM 2015 Signaling pathways in mouse and human trophoblast differentiation: a comparative review. Cellular and Molecular Life Sciences 72 1291-1302. (doi:10.1074/jbc.M115.659094)

Teshima S, Shimosato Y, Koiede T, Kuroki M, Kikuchi Y \& Aizawa M 1983 Transplantable choriocarcinoma of rats induced by fetectomy and its biological activities. Gann 74 205-212.

Val P, Martinez-Barbera J-P \& Swain A 2007 Adrenal development is initiated by Cited2 and Wt1 through modulation of Sf-1 dosage. Development 134 2349-2358. (doi:10.1242/dev.004390)

Van Doren SR 2015 Matrix metalloproteinase interactions with collagen and elastin. Matrix Biology 44-46 122-129. (doi:10.1016/j. matbio.2015.01.005)

Vo N \& Goodman RH 2001 CREB-binding protein and p300 in transcriptional regulation. Journal of Biological Chemistry 276 1350513508. (doi:10.1074/jbc.M009254200)

Watson ED \& Cross JC 2005 Development of structures and transport functions in the mouse placenta. Physiology 20 180-193. (doi:10.1016/j. cmet.2016.02.014)

Weiler H 2004 Mouse models of thrombosis: thrombomodulin. Thrombosis and Haemostasis 92 467-477.

Weninger WJ, Lopes Floro K, Bennett MB, Withington SL, Preis JI, Barbera JP, Mohun TJ \& Dunwoodie SL 2005 Cited2 is required both for heart morphogenesis and establishment of the left-right axis in mouse development. Development 132 1337-1348. (doi:10.1242/dev.01696)

Withington SL, Scott AN, Saunders DN, Lopes Floro K, Preis JI, Michalicek J, Maclean K, Sparrow DB, Barbera JP \& Dunwoodie SL 2006 Loss of Cited2 affects trophoblast formation and vascularization of the mouse placenta. Developmental Biology 294 67-82. (doi:10.1016/j.ydbio.2006.02.025)

Xu B, Qu Z, Gu S, Doughman Y-Q, Watanabe M, Dunwoodie SL \& Yang Y-C 2008 Cited2 is required for fetal lung maturation. Developmental Biology 317 95-105. (doi:10.1016/j.ydbio.2008.02.019)

Yin Z, Haynie J, Yang X, Han B, Kiatchoosakun S, Restivo J, Yuan S, Prabhakar NR, Herrup K, Conlon RA et al. 2002 The essential role of Cited2, a negative regulator for HIF-1 $\alpha$, in heart development and neurulation. PNAS 99 10488-10493. (doi:10.1073/pnas. 162371799)

Yoo J-Y, Kim TH, Lee JH, Dunwoodie SL, Ku BJ \& Jeong J-W 2015 Mig-6 regulates endometrial genes involved in cell cycle and progesterone signaling. Biochemical and Biophysical Research Communications 462 409-414. (doi:10.1016/j.bbrc.2015.04.146)

Received 21 November 2015

First decision 4 January 2016

Revised manuscript received 10 February 2016

Accepted 25 February 2016 